\title{
TOWARDS BODY LANGUAGE INVESTIGATION: A CONTRASTIVE SURVEY OF UNCOVERING AREAS OF CONVERGENCES AND DIVERGENCES BETWEEN ENGLISH AND ARABIC FACIAL EXPRESSIONS
}

\section{Prof. Dr. Qasim Abbas Dhayef (Ph.D) ${ }^{1} \quad$ Hasan Ali Hussein ${ }^{2}$}

\footnotetext{
${ }^{1}$ English Department, College of Education for Human Sciences, Babylon University, Iraq,

E-mail: qasimabbas@uobabylon.edu.iq

2 Department of English, Mazaya University College, Iraq

Email: hass29000@gmail.com
}

HNSJ, 2022, 3(1); https://doi.org/10.53796/hnsj3143

Published at 01/01/2022

Accepted at 27/12/2021

\begin{abstract}
Nonverbal communication is of various realizations across the world's languages where body language (henceforth BL) is one of its manifestations. The present study is concerned with investigating BL in standard English and standard Arabic to uncover the areas of convergences and divergences of facial expressions. The study is based on three hypotheses. First, some facial expressions tend to have the same forms and meanings in both languages. Second, due to cultural differences, some English facial expressions are probably absent in Arabic and vice versa. Third, when English-speaking people communicate, they are likely to use facial expressions more than Arabs are.

However, the data collected from both languages depend on a variety of sources that belong to different fields of knowledge (e.g. sociology, psychology, anthropology, linguistics and communication). After the data analysis carried out in the light of an eclectic model based on Van Els et al. (1984) and R. Lado (1957), the following conclusions were drawn. First, it has been remarked that some BL aspects have the same form in both languages, but they convey different meanings. Further, some have the same meaning in these two languages, but their forms are different.

Second, because of the cultures and languages interaction, some facial expressions transfer from one language into another. Third, facial expressions are considered to have the crucial role in communication because people look at each others' faces when they communicate. Fourth, it has been found out that one of the similarities between both languages is that some aspects of BL have been noticed to be similar in form and meaning alike. Accordingly, the first hypothesis has been accepted.

Fifth, the theoretical investigation has indicated that owing to cultural differences between both languages, some BL aspects have remained absent in Arabic or in English. This has verified hypothesis No. 2. Sixth, depending on the statistics of using BL by English-speaking people and Arabic-speaking people in the present study, one can conclude that English people use bodily movements (especially facial expressions) more than Arabs do because they believe that their language enjoys sanctity due to the fact that the Glorious Qur'an is written down in it. Notwithstanding the evidence, they stick to use it verbally and tend to minimize the nonverbal use of language. This has given rise to the higher frequency use of the spoken form by Arabic native speakers. This leads to verify the third hypothesis.

Seventh, one cannot figure out the BL aspects in his native language unless s/he investigates them. Therefore, some forms and meanings of Arabic BL aspects seem strange to Arabic-speaking people, but in fact they are Arabic BL aspects.
\end{abstract}

Key Words: 


\section{Introduction}

As a matter of fact, language is a means of communication used by people in any kind of social interaction. One salient kind of communication is BL which refers to the nonverbal signals that are used by people to communicate. According to Fast (1978) and Pease (2004), these nonverbal signals contribute a lot in daily communication, from one's facial expressions to his body movements, the things one does not say can still convey volumes of information. In terms of observable BL, nonverbal (non-spoken) signals are being exchanged whether these signals are accompanied by spoken words or not.

Furthermore, the study and theory of BL has become popular in recent years because psychologists have been able to understand what people say through their facial expressions, so as to translate humans' BL, revealing its underlying feelings and attitudes. BL is also commonly referred to as 'non-vocal communication', therefore, it is one of the salient types of nonverbal communication.

However, understanding BL is important, but it is also essential to note other cues such as context and to look at signals as a group rather than focusing on a single action. Further, one can learn more about some of the things to look for when he is trying to interpret BL, i.e., the context of situation. Generally speaking, researchers such as Birdwhistell (1970) and Mehrabian (1972) conclude that $\mathrm{BL}$ is thought to be ranging between $50 \%$ and $70 \%$ of man's communication.

For the purposes of this paper, the terms 'BL' and 'nonverbal communication' are frequently used. The view taken here is that BL is the main part of nonverbal communication which is the study of how people communicate face-to-face aside from the spoken words themselves. In this respect, the treatment of the topic here is to deal only with facial expressions and gestures. Accordingly, the present study is concerned with investigating this means of communication, i.e., BL and its salient types to highlight how it is utilized in the two languages.

Moreover, the use of BL in both languages, whether different or not, seems to be attributed to various reasons, some of which relate to the cultural differences. Therefore, the problem of this study stems from the actual difficulty inherent in interpreting and using the BL aspects by Arabic-speaking people and vice versa.

\section{Literature Review: Communication, Nonverbal Communication and Paralanguage}

\subsection{Communication}

Scholars and researchers have introduced too many definitions to the concept of communication. There is no generally accepted definition owing to the fact that each linguist offers a definition suitable to his perspective on the subject (Rothwell, 2000: 7). Therefore, Rothwell (ibid) simply defines communication as " a transactional process of sharing meaning with others". It has been investigated that this definition concentrates on the interactional aspect that happens between people when they are communicating to each other. But, he neglects important notions, for instance, the tools that humans use to get the meaning such as language, visual representation, gestures, etc.

Berge (1997: 95) insists that " a very simple and general, but neither unproblematic nor uncontroversial, way of defining communication is to view it as an information process going on between at least two human communicators (not necessarily two persons) embedded in a context, and a situation". Emphasizing on the linguistic context and context of situation in transferring information, he (ibid) overtly declares that "more specifically, communication can be defined as a generic term covering all messages uttered in different contexts and situations". Lyons (1990: 17) states that any communication system, including human languages, transmits meaning in terms of a 
message conveyed by a signal. The relation between the signal and its meaning is established by means of a code.

Communication, according to Akmajian et al. (2001: 363), is a social affair which usually takes place within the context of "a fairly well defined social situation". In such a context, the interlocutors rely on one another to share each other's conception of what the context is (ibid.). This means that the interlocutors need to share a view of social context to interpret each other's utterances and need to realize each other's roles and social identities. Having Natyavidushi's idea (2011:103) in hand, communication is "the art of passing information and the process by which meanings are exchanged so as to produce understanding as well as it is the process by which any massage is given or received through talking, writing and making gestures".

As a result, it has been mentioned in the opening that communication has different definitions and every expert on a certain field adopts a specific definition. However, what someone does or says (his or her symbolic behaviour) is interpreted as a message. As long as the behaviour of one person affects or influences the behaviour of another, communication is on the progress. Furthermore, a contrast which is often made, especially by psychologists, is between verbal and nonverbal communication to refer to the linguistic vs. non-linguistic features of communication. The latter includes facial expressions and gestures. Every time people knowingly or unknowingly send a verbal or nonverbal message to a friend or stranger, communication takes place.

\subsection{Elements and Types of Communication}

Before digging up the types of communication, one firstly should know that all communication interactions have certain elements in common which together help define the communication process. The better these elements are understood, the easier it will be for that one to develop his own communicative abilities. These elements can be listed in the points down below:

\subsubsection{Senders and Receivers}

Communication encounters take place between and among all types of senders (persons who encode messages) and receivers (persons who decode messages). Senders and receivers, respectively, are individuals who emit and take in messages (Tannen 1986 cited in Gamble \& Gamble, 2002: 9). Although it is easy to portray communication experience beginning with a sender and ending with a receiver, it is important to understand that during communication the role of sender does not belong exclusively to one person and the role of receiver to another. Instead, the processes of sending and receiving are constantly being reversed (ibid.).

\subsubsection{Content (Messages)}

People all send and receive both verbal and nonverbal messages during every communication encounter. What one talks about the words he uses to express his thoughts and feelings, the sounds he makes, the way he sits and gestures, his facial expressions, and even his touch or his smell, all communicate information. To this end, a message is the content of a communicative act (Gamble \& Gamble, 2002: 10).

Everything a sender or receiver does or says is a potential message as long as someone is there to interpret the behavior. When a person smiles, frowns, shouts, whispers, or turns away, he is communicating, and his communication is having some effect ( Guerrero \& Floyd, 2006: 11).

\subsubsection{Channels}

According to Crystal (2006: 3), who points out five modes of communication which are sound, sight, touch, smell and taste, because there are only five human senses. They can act as channels of information. Then he (ibid.) adds that "of course, if you believe in telepathy, you would need to recognize a 'sixth sense' available for communication; and perhaps there are life forms which interact 
using still other modes, such as the non-visible areas of electromagnetic spectrum". Thus, the information of the messages that humans send and receive using these modes is the meaning.

It is worth mentioning that Crystal (ibid.) maintains that "the five modes are not equally relevant for the transmission and reception of meaning". So, two of them do not play any role at all in human beings which are the olfactory (smell) and gustatory (taste) modes. In fact, humans do not routinely emit smell in order to communicate with others, and there is a very limited amount of information about outside world which humans can receive through the media of smell and taste.

A channel, therefore, can be defined as a medium by which a message is sent (Gamble \& Gamble, 2002: 10). People send and receive messages with and through all their senses. Equally, messages may be sent and received through verbal and nonverbal modes, or channels. Thus, people are multichannel communicators. For instance, they receive sound messages such as (they hear noises from the street), sight messages such as (they see how someone looks), taste messages such as (they enjoy the flavor of a particular food), smell messages such as (they smell the cologne a friend is wearing), and touch messages such as (they feel the roughness of a fabric) (ibid.).

\subsubsection{Noise, Feedback \& Effect}

Gamble and Gamble (2002: 11) have mentioned the terms Noise, Feedback and Effect. Noise is everything that interferes with or distorts people's ability to send and receive messages. Although human beings are accustomed to thinking of noise as some particular sound or group of sounds, the perceptive communicator realizes that noise can have both internal and external causes. However, internal noise is attributed to the psychological makeup, intellectual ability, or physical condition of the communicators whereas external noise is attributed to the environment. Thus, noise includes distractions such as a loud siren, a disturbing odor, and a hot room; personal factors such as prejudice, daydreaming, and feelings of inadequacy; and semantic factors such as uncertainty about what another person's words are supposed to mean (ibid.).

Feedback can be defined as the information returned to a message source. Whenever someone communicates with one or more persons, he receives information in return. The verbal and nonverbal cues that humans perceive in reaction to their communication function as feedback. Feedback tells someone how he is coming across. A smile, a frown, a chuckle, a sarcastic remark, a muttered thought, or simply silence in response to something people did or said can cause them to change, modify, continue, or end a transaction (ibid.).

As far as Effect is concerned, it can be defined as the communication outcome. As people communicate, they are changed in some way by the interaction, which in turn influences what follows. In other words, communication has an effect and can be viewed as an exchange of influences. This means that communication always has some effect on someone and on the person or people with whom he is interacting (ibid.).

\subsubsection{Context of Situation}

Communication always takes place in some context or setting. Sometimes context is so natural that people hardly notice it. Therefore, the context makes such an impression on them in that it exerts considerable control over their behavior (ibid.: 12). It can be considered to the extent to which one's present environment which influences the way he acts toward others or determining the nature of the communication encounters he shares with them. So, the environment and the nature of communication play major roles in determining the message and its meaning (ibid.). Thus, it can be taken into account the fact that sometimes conditions of place and time, i.e., context of situation can affect humans' communication without their consciously realizing it (Eisenberg \& Gamble, 1991: 22). This is shown 
clearly when humans reflect their personal feeling and attitudes by their facial expressions, postures, gestures and proxemics unintentionally (ibid.).

\subsection{Types of Communication}

Dealing with patterned human and animal communication in all its modes, it is agreed that communication is a much broader concept than language involving the transmission and reception of any kind of information between humans as well as between animals (Crystal, 2006: 3). Crystal (2008: 89) further adds that human beings communicate using two main forms: verbal communication and non-verbal communication.

\subsubsection{Verbal Communication}

Verbal communication is any form of communication that uses words in order to convey meaning or transmit messages. By the same token, Crystal (2008: 90) emphasizes this idea when he writes "the term 'verbal', implying that language is basically a matter of "words". The same notion is also discussed by him, but in a different phrasing when he (1994: 248) adopts another term which is verbal meaning and states that " verbal meaning relies on vowels and consonants to construct words, phrases, and sentences".

On the other hand, many scholars and linguists use the term 'linguistic' instead of 'verbal' for identifying this kind of communication. Following the same context, Hunter (2006: 66) states that "there is nothing, I think, essentially new about linguistic communication except that it involves speech acts done with words having a conventional meaning". Thus, the word 'linguistic' is used as a synonym of the word 'verbal' (ibid.).

Put it in another way, verbal communication involves "determining who says what to whom; where and when it is said; and how and why it is said; that is, it is motivated and shaped by the setting, the message contents, the participants, and the goals of each interlocutor" (Danesi, 2004: 107).

\subsubsection{Non-Verbal Communication}

Whereas verbal communication often refers to the words people use in communication, nonverbal communication (Henceforth NVC) refers to communication that is produced by some means other than words (e.g. eye contact, bodily movements, or vocal cues) (Knapp and Hall, 2006: 5). Trask (2007: 187) refers simply to NVC as "any aspect of communication which does not involve words". Finch (2005: 222) defines NVC as "communication that takes place other than through words". Samovar, Porter and McDaniel (2010: 246) propose that "NVC involves all those non-verbal stimuli in a communication setting that are generated by both the source and his or her use of the environment and that have potential message value for the source or receiver".

Having a variety of views on NVC, it seems that NVC is done without words. This is supported by Natyavidushi (2011: 103), when he agrees with the previous scholars stating that NVC is usually "understood as the process of communication through sending and receiving of wordless messages and can be communicated through gesture, touch, posture, facial expressions and eye contact". But Natyavidushi (2011: 103) asserts that communication cannot be achieved unless there is a direct transaction between humans aiming at focusing on face-to-face interaction.

\subsubsection{Types of NVC}

Two types of NVC relevant to linguistics are mentioned by Finch (2005: 222) and Trask (2007: 187). These are in what follows:

\subsubsection{Paralanguage}

According to Trask (ibid.:205), "Paralanguage is the non-linguistic aspects of speaking". In other words, when people speak, they communicate a good deal of purely linguistic information to their listeners. In addition, they make use of strictly non-linguistic variables like pitch, loudness, 
tempo, timbre and voice quality. The use of these variables conveys information about people's mood and attitude; about whether they are angry, amused, nervous, excited, impatient, tired or whatever. These aspects of speaking are collectively called paralanguage or, informally, tone of voice (ibid.).

Crystal (2008: 349), however, elaborates in defining paralanguage and he emphasizes that "paralanguage is a term used in suprasegmental phonology to refer to variations in tone of voice which seem to be less systematic than prosodic features (especially intonation and stress)". Then, he (ibid.) provides examples of paralinguistic features saying that:

They would include the controlled use of breathy or creaky voice, spasmodic features (such as giggling while speaking), and the use of secondary articulation (such as lip-rounding or nasalization) to produce a tone of voice signaling attitude, social role, or some other language-specific meaning.

\subsubsection{Body Language}

Finch (ibid.) claims that BL is the second component of non-vocal communication including gestures, facial expressions, posture, and eye movement. He tries to emphasize that BL does not have any vocal aspects. In other words, it particularly depends on the body and its movements. Using Sebeok's own words (2001: 20), "the body by itself can be a prime tool for communication, verbal as well as nonverbal".

This can be supported by Crystal (2006: 5), when he states that the meanings of the bodily behavior features are "all fairly 'primitive' expressions of attitudes or social relationship, such as affection, aggression, sexual attraction, greeting, congratulation, gratitude, surprise, and the signalling of attention".

\subsection{BL Aspects}

Tackling the major aspects or components of BL, the present study will depend on several scholars' classifications such as, Fast (1991), Pease and Pease (2004), Rothwell (2000), Gamble and Gamble (2002), Samovar, Porter and McDaniel (2010), and Chapman (2009-2012). Though this study follows the classifications made by the scholars mentioned above, certain modifications should be made. Therefore, an eclectic model will be adopted. Such a model will facilitate the investigation in question of BL aspects in both languages (English and Arabic).

Table (1) Facial Expressions in English

\begin{tabular}{|l|l|}
\hline Facial Expressions in English & Figures of Facial Expressions \\
\hline
\end{tabular}

A Smiling Facial Expression Conveying Happiness

A Gloomy Facial Expression Conveying Sadness

Terrified Facial Expression Conveying Fear Figures of Facial Expressions 
A Disgusted Facial Expression Conveying Disgust

An Astonishing Facial Expression Conveying Surprise

A Frowning Facial Expression Conveying Anger

Tongue-Show Conveying Disagreement or Displeasure

Lip-Pout Expressing Disappointment or Sadness

Tense-Mouth Expressing Anger, Frustration

The Facial Expression of Stiff-Upper-Lip

The Eyebrows Slightly Raised Signaling Greeting and
Recognition.


Blank Face Revealing "Do not disturb"

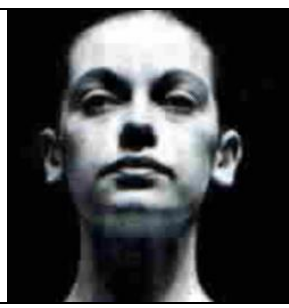

Hence, many aspects of BL are there in both languages such as proxemics (personal space), postures (body positions), head movements, eye movements, eye contact, facial expressions and gestures. This study is concerned only with facial expressions. This is due to the fact that such expressions have debated the most challenging areas among different people within different cultures. Thus, the researcher is going to dig up these expressions for the purpose of uncovering their convergences and divergences in both English and Arabic languages.

\subsubsection{Facial Expressions in English}

As far as facial expressions in English are concerned, they can be defined as the act of communicating a mood, attitude, opinion, feeling, or other message by contracting the muscles of the face (Fridlund,1994: 31). However, better than any parts of a human body, people's faces reveal emotions, opinions, and moods. While people learn to manipulate some expressions (e.g., smile), many unconscious facial expressions (e.g., tongue-show) reflect their true feelings and hidden attitudes. Many facial expressions are universal, though most may be shaped by cultural usages and rules (Givens, 2006: 71). The facial expressions which will be introduced are shared by Englishspeaking people. The table plotted above shows the most frequent facial expressions used by Englishspeaking people.

Following the table, the first facial expression in English indicates a true smile of happiness, gladness, or joy in which the corners of the mouth curve upward, and the outer corners of the eyes crinkle into crow's feet (ibid.). The second shows an unpleasant feeling of sorrow, unhappiness, depression, or gloom. Signs of sadness show in the crying face and lip-pout expression. They include drooping eyelids, flaccid muscles, lowered lips, cheeks, and jaw "all sink downwards from their own weight". This leads to indicate that sadness shows most clearly in the eye area (ibid.).

Third, fear will make one raises his brows, widens his eyes, and possibly opens his mouth. All these responses will increase one's ability to see and think quickly in the face of real threat (James, 2009: 123). Fourth, disgust will prevent one from eating food that has gone bad or would poison him. This expression clamps the teeth together and twists one's mouth, closes his eyes, and makes him wrinkle his nose and turn his head away, often from side to side (ibid.). Fifth, the facial expression of surprise is similar to the facial expression of fear but surprise expression is accompanied with a happy context. It also will make a person raises his brows, widens his eyes, and possibly opens his mouth (ibid.). Sixth, anger creates a frown that protects one's eyes in any potential fight. It also tightens the lips over the teeth, flares the nostrils, and puffs out and reddens his face, making him look more terrifying (ibid.: 124).

Seventh, tongue-show is a momentary protrusion of the tongue between the lips. It is a universal mood sign of unspoken disagreement, disbelief, disliking, displeasure, or uncertainty. It may modify, counteract, or contradict a verbal remark. It refers to show the statement "Yes, I agree" and to indicate a suggestion of the statement "I do not agree" (Givens, 2006: 71). Eighth, lip-pout in English is used as to push the lower lip against the upper in a protruded look of disappointment, displeasure, sadness, or uncertainty (Givens, 2006: 71). Ninth, the tense-mouth has been observed as a sign of anger, frustration, and threat, or of cognitive processing (e.g., while pondering, thinking, or feeling uncertain) (ibid.: 73). 
Taking the tenth column into account, Pease and Pease (2004: 115-16) state that the Lips-Pursed is an expression still used today by English-speaking people when they feel they are being intimidated by inferior people and this gesture is often accompanied by extended eye blinks. Eleventh, This facial expression signals the statement "I recognize you!" or "Hello". Every time people see someone that they know or that they are accepting, their eyebrows flash, i.e., they rise up them a little very quickly (Bowden, 2010:111).

Finally, English-speaking people adopt the blank face expression at home while resting, reading, and watching TV alone. It just sends a strong emotional message: "Do Not Disturb". In shopping malls, elevators, or subways, e.g., people adopt neutral faces to distance themselves from strangers. The blank face is a subtle sign used to keep others a polite distance away (Givens, 2006: 74). After having a look at how facial expressions in English might be formed, it is time to deal with facial expressions in Arabic.

\subsubsection{Facial Expressions in Arabic}

As a matter of fact, Arabic is like other languages in that it undergoes semantic change. Many Arabic words have changed their meaning. The meanings of the bodily movements have also changed because Arabic modern linguists have not tried to uncover the old meanings of those bodily movements, for example, the old meaning of the shoulders shrug is happiness and acceptance while nowadays its meaning has become refusal and denial because of the dominant western culture (Dawud, 2007: 18). Therefore, most of the examples, concerning facial expressions, that will be cited in this study are taken from the Qur'an because their meanings have not changed yet and they still have the same meanings in the present-day Arabic.

However, the face is more capable than other organs of showing the psychological traces completely because the obvious conditions in the face are powerful guidance of the inward morals such as shyness, fear, anger, happiness, and depression in which each of them has a particular condition reflected on the face rather than the rest of the body (Al-Ansary, 2005: 58).

What is more, Ekman, Friesen and Sorenson supported some of Darwin's original beliefs about inborn gestures when they studied the facial expressions of people from five widely different cultures. They found that each culture used the same basic facial expressions to show emotions, which led them to the conclusion that these expressions must be inborn (Pease, 1981:8). Consequently, it has been realized that facial expressions are universal. So, Arabic-speaking people share these emotional expressions which are happiness, sadness, fear, disgust, surprise and anger.

As a result, it is noticed by Arab linguists and theologists that the six universal facial expressions are mentioned in the Glorious Qur'an in several places in which the face and its shapes are the first motive and expressive guides for the meanings of these shapes (see Fayadh, 2011: 248-75). The most frequent facial expressions in Arabic are listed in the table below.

Table (2) Facial Expressions in Arabic

\begin{tabular}{|c|c|}
\hline Facial Expressions in Arabic & Examples of Facial Expressions in Arabic \\
\hline $\begin{array}{l}\text { A Smiling Facial Expression Showing } \\
\text { Happiness and Joy }\end{array}$ & 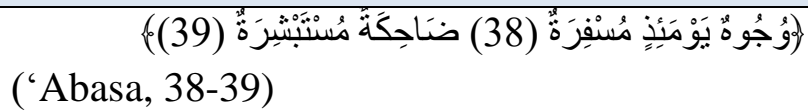 \\
\hline $\begin{array}{l}\text { A Gloomy Facial Expression Showing } \\
\text { Sadness and Depression }\end{array}$ & 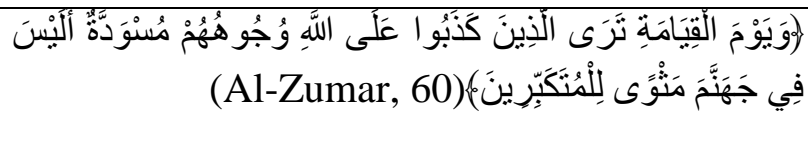 \\
\hline $\begin{array}{l}\text { A Terrified Facial Expression Showing } \\
\text { Fear }\end{array}$ & 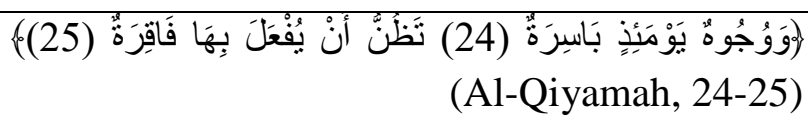 \\
\hline $\begin{array}{l}\text { A Disgusted Facial Expression Showing } \\
\text { Disgust Related to Anger }\end{array}$ & 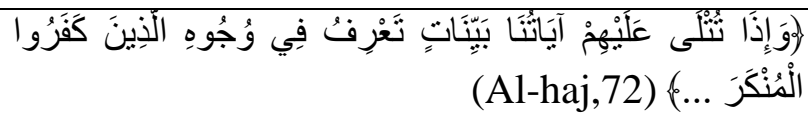 \\
\hline
\end{tabular}




\begin{tabular}{|c|c|}
\hline $\begin{array}{l}\text { An Astonishing Facial Expression } \\
\text { Showing Surprise }\end{array}$ & 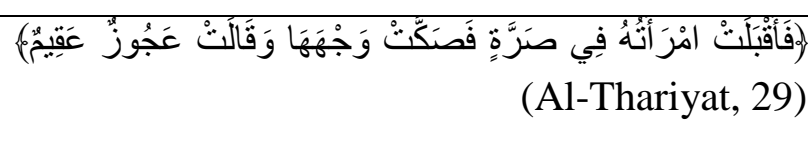 \\
\hline $\begin{array}{l}\text { A Frowning Facial Expression Showing } \\
\text { Anger }\end{array}$ & 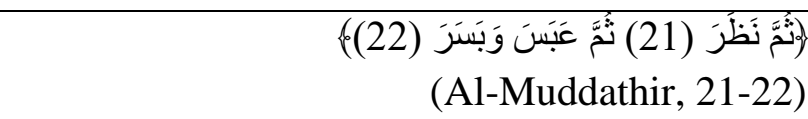 \\
\hline $\begin{array}{l}\text { The Facial Expression of a Small Smile } \\
\text { Conveying Greeting }\end{array}$ & 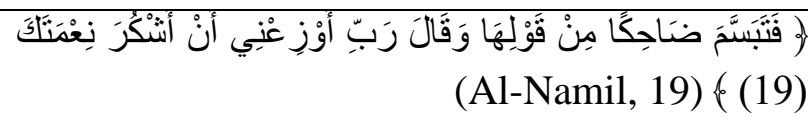 \\
\hline $\begin{array}{l}\text { The Facial Expression of Biting The } \\
\text { Lower Lip Conveying Anger, Frustration } \\
\text { or Regret }\end{array}$ & $\begin{array}{r}\text { عضضت على شفتي و اجشت في بكاء حار } \\
\text { (Barakah, 2004:91) }\end{array}$ \\
\hline $\begin{array}{l}\text { A Facial Expression of Teeth-Show } \\
\text { Conveying Mockery }\end{array}$ & $\begin{array}{l}\text { It is performed by showing one's teeth. It } \\
\text { expresses a false smile or mockery. Otherwise, } \\
\text { it is done by showing one's tongue. It also } \\
\text { signals sarcasm and mockery (Dawud, 2007: } \\
60-62 \text { ). }\end{array}$ \\
\hline $\begin{array}{l}\text { The Facial Expression of Biting The } \\
\text { Teeth Conveying Patience and Toughness }\end{array}$ & $\begin{array}{l}\text { It is performed by biting one's teeth. This } \\
\text { action expresses patience, toughness or } \\
\text { commitment (Dawud, 2007: 63). }\end{array}$ \\
\hline $\begin{array}{l}\text { The Facial Expression of Biting Woman's } \\
\text { Lower Lip Conveying Seduction }\end{array}$ & $\begin{array}{l}\text { Biting the lower lip performed by only females } \\
\text { signals a sexual seduction ('arar, 2007: 275). }\end{array}$ \\
\hline
\end{tabular}

Following the table plotted above, the first facial expression shows that faces are bright laughing because of the great happiness which appears on heaven residents' faces (Ibin Katheer, 1994: 327). Second, faces might be black in the sense that they are in a great sorrow due to people ugly deeds in the worldly life and they ignore the afterlife. So, they are very sad and very depressed (Rabay'a, 2010: 52). Third, such a description belongs to the disbelievers when they are standing in front of Allah to sue and they know that they will go to hell due to their ugly deeds in the worldly life. Therefore, they are very frightened because of their unhappy end (ibid.: 53).

Fourth, the bodily status in the ayah mentioned in the fourth column signals the meaning of disgust, hatred and anger in which there is a meaningful description to the condition of disbelievers (ibid.). Fifth, the ayah mentioned in the fifth column indicates the meaning of surprise which is performed by hitting the face. However, this action of hand is connected to the face and takes the meaning of astonishment in the Arabic-speaking communities (ibid: 55). Sixth, a facial expression may also refer to the inner psychological condition of people. Thus, they become angry due to what they hear (ibid.).

However, it has been investigated (see Fayadh, 2011: 248-75) that the above mentioned facial expressions in Arabic-speaking communities are similar to the universal ones. Overtly, these facial expressions are of the description of the bodily conditions, but covertly they are depiction of the psychological conditions. Furthermore, some facial expressions convey certain meanings in Arabicspeaking communities. They are indicated by the seventh and eighth, ninth, tenth and eleventh columns. The expression indicated by the seventh column shows that an Arabic-speaking person will expand his face by a smile if someone comes to visit or greets him. It is considered to be one of the main elements of hospitality. As for the eighth column, it is performed by pouting one's lips. It expresses anger, frustration or regret. The similar meaning can be done by biting his lower lip (Rabay'a, 2010: 55). The ninth, tenth and eleventh columns are clarified in the table above. 


\section{Methodology}

As a sub-discipline of linguistics, contrastive analysis is concerned with "the comparison of two or more languages or subsystems of language in order to determine both differences and similarities between them" (Fisiak, 1981: 1). Splitting a great deal of ink on the models of analysis, this study adopts Lado's model (1957) that is used to pinpoint the form, meaning and distribution of BL aspects in both languages and it also adopts Van Els et al. (1984) model in which CA is used to show the points of similarity and difference.

Putting the two models in one basket, the same procedures in comparing English and Arabic languages have been held to show their 'likenesses' and 'differences'. But, these two models have slight differences in conducting such a study. So, an eclectic model will be designed by the researcher so that accurate and reliable results will be gauged. Furthermore, Lado's model has the advantage of comparison of cultures. The model will be employed here since the present study is concerned with both languages which belong to two totally different cultures.

However, Lado's model has three facets: form, meaning and distribution. Due to the fact that the facial expressions of English and Arabic do not have specific distributions, the last principle (i.e., distribution) will be neglected here since this principle is irrelevant to the study in question. What matters here is that the form and meaning have significant roles in this study since the two languages exhibit convergences the area under study (e.g. similar in form and meaning) and divergences (e.g. some BL aspects differ in form and meaning). In addition, some differ in form but have similar meaning while others differ in meaning but have different forms. The following subsections will be devoted to the comparison of English and Arabic BL (e.g., facial expressions) in terms of form and meaning.

\section{Analysis of Facial Expressions}

As mentioned in the theoretical section (see 2.5.2 ), six of facial expressions are universal, i.e., they have the same forms and meanings in all cultures. However, English has similar forms and meanings to the Arabic counterparts which are a smiling facial expression conveying happiness, a gloomy facial expression signaling sadness, a terrified facial expression expressing fear, a disgusted facial expression referring to disgust, an astonishing facial expression signifies surprise and a frowning facial expression signaling anger.

Moreover, in English, the facial expression of lip-pout is similar to pouting the lips in Arabic, but this form does not have the same meaning. In English it signifies disappointment and sadness while in Arabic it conveys anger, frustration or regret. Furthermore, the facial expression of tensemouth in English and the facial expression of pouting the lips or biting the lower lip in Arabic share the same meaning which is anger, frustration or cognitive processing. Similarly, the expressing of greeting and recognition has different forms where the facial expressions of the eyebrows are slightly raised in English and the facial expression of a small smile in Arabic.

Finally, some English facial expressions do not have their equivalents in Arabic such as, the facial expression of tongue-show conveying disagreement or displeasure, the facial expression of blank face signaling "Do not disturb" and the facial expression of English stiff-upper-lip expressing the impression of being in a complete emotional control. Nevertheless, some Arabic facial expressions do not exist in English. They are as follows: the facial expression of teeth-show signaling mockery, the facial expression of biting the teeth conveying patience and toughness, and finally the facial expression of biting the woman's lower lip. Consider the following table: 
Table (3) The Forms and Meanings of Facial Expressions in English and Arabic

\begin{tabular}{|c|c|c|}
\hline & English & Arabic \\
\hline & \multicolumn{2}{|l|}{ Form } \\
\hline & A Smiling Facial Expression. & $\begin{array}{l}\text { A Smiling Facial Expression. } \\
\text { (The Same Form) }\end{array}$ \\
\hline & \multicolumn{2}{|l|}{ Meaning } \\
\hline 1 & It conveys happiness. & Same as in English. \\
\hline \multirow{4}{*}{2} & \multicolumn{2}{|l|}{ Form } \\
\hline & A Gloomy Facial Expression. & $\begin{array}{l}\text { A Gloomy Facial Expression. } \\
\text { (The Same Form) }\end{array}$ \\
\hline & \multicolumn{2}{|l|}{ Meaning } \\
\hline & It conveys sadness. & Same as in English. \\
\hline \multirow{4}{*}{3} & \multicolumn{2}{|l|}{ Form } \\
\hline & A Terrified Facial Expression. & $\begin{array}{l}\text { A Terrified Facial Expression. } \\
\text { (The Same Form) }\end{array}$ \\
\hline & \multicolumn{2}{|l|}{ Meaning } \\
\hline & It conveys fear. & Same as in English. \\
\hline \multirow{4}{*}{4} & \multicolumn{2}{|l|}{ Form } \\
\hline & A Disgusted Facial Expression. & $\begin{array}{l}\text { A Disgusted Facial Expression. } \\
\text { (The Same Form) }\end{array}$ \\
\hline & \multicolumn{2}{|l|}{ Meaning } \\
\hline & It conveys disgust. & Same as in English. \\
\hline \multirow{4}{*}{5} & \multicolumn{2}{|l|}{ Form } \\
\hline & An Astonishing Facial Expression. & $\begin{array}{l}\text { An Astonishing Facial Expression. } \\
\text { (The Same Form) }\end{array}$ \\
\hline & Meaning & \\
\hline & It conveys surprise. & Same as in English. \\
\hline \multirow{4}{*}{6} & \multicolumn{2}{|l|}{ Form } \\
\hline & A Frowning Facial Expression. & A Frowning Facial Expression. \\
\hline & \multicolumn{2}{|l|}{ Meaning } \\
\hline & It conveys anger. & Same as in English. \\
\hline \multirow{4}{*}{7} & \multicolumn{2}{|l|}{ Form } \\
\hline & The Facial Expression of Lip-Pout. & $\begin{array}{l}\text { The Facial Expression of Pouting The } \\
\text { Lips. (The Same Form) }\end{array}$ \\
\hline & \multicolumn{2}{|l|}{ Meaning } \\
\hline & It conveys disappointment or sadness & It conveys anger, frustration or regret. \\
\hline \multirow{4}{*}{8} & \multicolumn{2}{|l|}{ Form } \\
\hline & $\begin{array}{l}\text { The Facial Expression of Tense- } \\
\text { Mouth. }\end{array}$ & $\begin{array}{l}\text { The Facial expression of Pouting } \\
\text { The Lips or Biting The Lower Lip. }\end{array}$ \\
\hline & \multicolumn{2}{|l|}{ Meaning } \\
\hline & $\begin{array}{l}\text { It conveys anger, frustration or } \\
\text { cognitive processing. }\end{array}$ & Same as in English. \\
\hline \multirow[b]{2}{*}{9} & \multicolumn{2}{|l|}{ Form } \\
\hline & $\begin{array}{l}\text { The Facial Expression of The } \\
\text { Eyebrows Slightly Raised. }\end{array}$ & A Facial Expression of a Small Smile. \\
\hline
\end{tabular}




\begin{tabular}{|c|c|c|}
\hline & \multicolumn{2}{|l|}{ Meaning } \\
\hline & It conveys greeting and recognition. & Same as in English. \\
\hline \multirow{4}{*}{10} & \multicolumn{2}{|l|}{ Form } \\
\hline & $\begin{array}{l}\text { The Facial Expression of Blank } \\
\text { Face. }\end{array}$ & The Facial Expression of Teeth Show. \\
\hline & \multicolumn{2}{|l|}{ Meaning } \\
\hline & It conveys mockery. & It conveys mockery. \\
\hline \multirow{4}{*}{11} & \multicolumn{2}{|l|}{ Form } \\
\hline & $\begin{array}{l}\text { The Facial Expression of The } \\
\text { English Stiff-Upper-Lip. }\end{array}$ & $\begin{array}{l}\text { The Facial Expression of Biting The } \\
\text { Teeth. }\end{array}$ \\
\hline & \multicolumn{2}{|l|}{ Meaning } \\
\hline & $\begin{array}{l}\text { It gives the impression of being in a } \\
\text { complete emotional control. }\end{array}$ & It conveys patience and toughness. \\
\hline \multirow{4}{*}{12} & \multicolumn{2}{|l|}{ Form } \\
\hline & $\begin{array}{l}\text { The Facial Expression of Tongue- } \\
\text { Show. }\end{array}$ & $\begin{array}{l}\text { The Facial Expression of Biting The } \\
\text { Woman's Lower Lip. }\end{array}$ \\
\hline & \multicolumn{2}{|l|}{ Meaning } \\
\hline & $\begin{array}{lll}\text { It conveys disagreement or } \\
\text { displeasure. }\end{array}$ & It conveys seduction. \\
\hline
\end{tabular}

\section{Results}

The present study has come up with some findings based on a contrastive survey. They are of two types: similarities and differences.

\subsection{Similarities}

The convergences between English and Arabic as far as BL aspects are concerned have the same form and the same meaning. Therefore, Arab learners of English as a foreign language would not face any problem in using and interpreting them. They are as follows:

1. A Smiling Facial Expression in both languages.

2. A Gloomy Facial Expression in both languages.

3. A Terrified Facial Expression in both languages.

4. A Disgusted Facial Expression in both languages.

5. An Astonishing Facial Expression in both languages.

6. A Frowning Facial Expression in both languages.

\subsection{Differences}

\subsubsection{Similar Forms with Different Meanings}

Arab learners of English as a foreign language and English learners of Arabic as a foreign language are expected to counter problems in using and interpreting BL aspects. Concerning facial expressions, one of these expressions has the same form with different meanings. It is the facial expression of 'lip-pout'. In English, it is used to convey disappointment or sadness. Whereas in Arabic, it conveys anger, frustration or regret.

\subsubsection{Similar Meanings with Different Forms}

Some facial expressions have the same meaning, but different forms in both languages. They are as follows:

1. The facial expression of Tense-Mouth in English and the facial expression of pouting the lips or biting the lower lip in Arabic. 
2. The facial expression of the Eyebrows slightly raised in English and a facial expression of a small smile in Arabic.

\subsubsection{Totally Different in Form and Meaning in Both Languages}

Some facial expressions are used only in English. Some are used in Arabic exclusively. These kinds of BL aspects are culture-specific. They are as follows:

1. The facial expression of blank face in English.

2. The facial expression of English stiff-upper-lip in English.

3. The facial expression of teeth-show in Arabic.

4. The facial expression of biting the teeth in Arabic.

\subsubsection{The Transferred Facial Expressions between Both Languages}

Some facial expressions are specifically found in English and some particularly exist in Arabic. Because of the process of cultures and languages interaction, some of them might be used in both languages, such as

1. The Facial Expression of Tongue-Show can be used in both English and Arabic. But in Arabic, such a facial expression is used mostly by females.

2. The Facial Expression of Biting The Woman's Lower Lip in both English and Arabic.

3. The Facial Expression of Biting The Teeth in both English and Arabic.

4. The Facial Expression of The English Stiff-Upper-Lip in English.

\section{Conclusions}

The theoretical surveys of BL, particularly of 'facial expressions' on the basis of which the CA was carried out in English and Arabic, have yielded the following conclusions:

1. It has been remarked that some BL aspects have the same form in both languages, but they convey different meanings. Further, some have the same meaning in these two languages, but their forms are different.

2. Because of the cultures and languages interaction, some facial expressions transfer from one language into another.

3. Facial expressions are considered to have the crucial role in communication because people are looking at each others' faces when they communicate.

4. It has been found out that one of the similarities between both languages in that some aspects of BL (e.g., facial expressions) have been noticed to be similar in form and meaning alike. This leads to verify the first hypothesis.

5. The theoretical investigation has indicated that owing to cultural differences between both languages, some facial expressions have remained absent in Arabic or in English. This verifies hypothesis two.

6. Depending on the qualitative analysis of using BL by English-speaking people and Arabicspeaking people in the present study, one can conclude that English people use bodily movements (especially facial expressions) more than Arabs do because they believe that their language enjoys sanctity due to the fact that Glorious Qur'an is written down in it. Consequently, they stick to use it verbally and tend to minimize the nonverbal use of language. This has given rise to the higher frequency use of the spoken form by Arabic native speakers. In this regard, the third hypothesis of the present study has been proved. 


\section{Reference List}

Akmajian, A., Deemers, R. A., Farmer, A. K. and Harnish, R. A. (2001). Linguistics: An Introduction to Language and Communication. $\left(5^{\text {th }} \mathrm{ed}\right.$.) London: the MIT Press.

Al-Ansary, Mohammed Bin Abi-Talib (d.737 h, 2005). Al-Siyasa Fi 'ilm Al-Farasa. Ahmed Farid Al-Mezidi (ed.). Beirut: Dar Al-Kutub Al-'ilmiyah.

'arar, M. A. (2007). Al-Bayan Byla Lysan (A Study in Body Language). Beirut: Dar Al-Kutub Al'ilmiyāh.

Barakah, E. (2004). Perfume for Women. Beirut: Dar Al-Hadarah for Publishing.

Berge, L. K. (1997) 'Communication'. In Lamarque, V. P. (ed.) (1997). Concise Encyclopedia of Philosophy of Language. Oxford: Elsevier Ltd. pp. 95-101.

Birdwhistell, L. R. (1970). Kinesics and Context. Philadelphia: University of Pennsylvania Press. Bowden, M. (2010). Winning Body Language. New York: McGraw-Hill.

Chapman, A. (2009-12) http://www.businessballs.com/body-language.htm. Accessed in 03/4/2021.

Crystal, D. (1994). The Cambridge Encyclopedia of English Language. London :BCA.

Crystal, D. (2006). How Language Works. London: Penguin Books.

Crystal, D. (2008). A Dictionary of Linguistics and Phonetics. (6 ${ }^{\text {th }}$ ed.) London: Blackwell Publishing.

Danesi, M. (2004). Messages, Signs, and Meanings. ( $3^{\text {rd }}$ ed.) Toronto: Canadian Scholars' Press Inc. Dāwūd, M. M. (2007). Jasad Al-insan wa Al-Ta'birat Al-Lighawiyah: Dirrasa Dalalia wa

Ma'jamia(The Human Body and The Linguistic Expressions: Lexical and Semantic Study). Cairo: Dar Ghariib for Printing, Publishing and Distribution.

Eisenberg, A. \& Gamble, T. (1991). Painless Public Speaking: A Work Text Approach. London \&

New York: University Press of America.

Fast, J. (1978). Body Language. London: Pan Books Ltd.

Fayyadh, H. (2011). "Facial Expressions in AL-Qur'an AL-Kareem". University of Anbar: 2 (5) 2011. Iraq: Education College for Women.

Finch, G. (2005). Key Concepts in Language and Linguistics.( $2^{\text {nd }}$ ed.) New York: Palgrave Macmillan.

Fisiak, J. (1981). Contrastive Linguistic and The Language Teacher.

Fridlund, Alan J. (1994). Human facial expression (1 ed.). San Diego: Academic Press.

Gamble, K. T. and Gamble, M. (2002). Communication Works ( $7^{\text {th }}$ ed.) New York: McGraw-Hill.

Givens, B. D.(2002). The Nonverbal Dictionary of Gestures, Signs \& Body Language Cues.

http://www.center-for-nonverbal-studies.org/6101.html. Accessed in 9/4/2021.

Guerrero, L. \& Floyd, K. (2006). Nonverbal Communication in Close Relationships. Lawrence

Erlbaum Associates, Inc.: London.

Ibin Kathir, Isma'il Bin 'umar (d.774 h, 1994) Tafsir Al-Qur'an Al'adiim (The Commentary on the

Great Qur'an). Mahmood Hassan (ed.) Beirut: Dar Alfikr.

James, J. (2009). The Body Language Rules. Illinois :Sourcebooks, Inc.

Knapp, M. and Hall, J. (2006). Nonverbal Communication in Human Interaction. (6 $6^{\text {th }}$ ed.)

Belmont: Thomson Wadsworth.

Lado, R. (1957). Linguistics Across Cultures: Applied Linguistics for Language Teaching. AnnArbor: The University of Michigan Press.

Lyons, J. (1990) Language and Linguistics: An Introduction. Cambridge: Cambridge University Press.

Mehrabian, A. (1972). Nonverbal Communication. New Jersey: Transaction Publishers. 
Natyavidushi, J. (2011). Importance of Body Language in Effective Multicultural Communication. Karnataka: University of Craiova. Oxford: Oxford Pergamon Press.

Pease, A. (1981). Body Language: How to Read Others' Thoughts by Their Gestures. London: Sheldon Press.

Pease, A. and Pease, B. (2004). The Definitive Book of Body Language. Buderim: Pease International.

Rabay'a, Isama, Jamil, Abdul-Ghany. (2010). Lughat Al-Jasad Fi Al-Qur'an Al-Kareem (Body Language in The Glorious Qur'an). Nablis: The National University of Al-Najah Press.

Rothwell, J. D. (2000). In the Company of Others: An Introduction to Communication. New York: McGraw-Hill.

Samovar, A. L., Porter, E. R. and McDaniel, R. E. (2010). Communication Between Cultures. $\left(7^{\text {th }}\right.$ ed.) Boston: Wadsworth.

Sebeok, A. T. (2001.) An Introduction to Semiotics.(2 ${ }^{\text {nd }}$ ed.) Toronto: University of Toronto Press.

Trask, L. R. (2007). Language and Linguistics: The Key Concepts. Ed. by Peter Stockwell (2 ${ }^{\text {nd }}$ ed.) New York: Routledge.

Van Els et al. (1984). Applied Linguistics and The Learning and Teaching of Foreign Languages.

London: Edward Arnold. 